\title{
A Living Quilt: The Journey of a Cohort of Emerging Arts Therapists in Aotearoa
}

\author{
MAAT Year 3 2018: Allie Manners, Arijana Ruznic-Beyer, \\ Ayaka Shima, Beth McGuinness, Brett Harrington, Carrie \\ Leigh, Danielle Mitchell, Eve Cunnane, Istvan Csata, \\ Judy O'Byrne, Julie Dobson, Louise Morton, Mary Weir, \\ Naomi Pears-Scown, Renee Barker, Rosa Heney, Ruth \\ Foulkes, Sarah Moore, Scarlett Jeong, Serena Corless \\ Whitecliffe College of Arts and Design, New Zealand
}

\begin{abstract}
This article traces the collaborative creation of a final gift-a symbolic weighted quilt-recently given by a cohort of third year trainee arts therapists to their faculty and fellow students. The article uses poetry and narrative to present and explore the process of this group of emerging arts therapists being woven together via their experiences of creativity, uncertainty and trust during their time on the Master of Arts in Arts Therapy program. It notes the interconnectivity between the singular and shared identities found during this journey, and explores the precious, expansive, and universal nature of the arts therapy experience and profession. This creative collaboration is a representation of the experience of student arts therapists who, having been soaked in the heavy liquids of creative encounters and felted together as a community, are now on the cusp of taking this deep fluid identity and experience out into the wider community.
\end{abstract}

Keywords: quilt, weighted blanket, emerging arts therapists, Aotearoa, poetry

The heavy blanket lies at the centre of the room, occupying both physical and emotional space. Its eight-kilogram weight is spread out over an area of 1.5 metres by 2 metres; its great back is covered in a quilt of vivid colours. This patchwork top consists of 20 squares of robust fabrics - velvet, denim, polyester, calico, wool - each with a unique pattern or image stitched, painted or embroidered upon its fabric. It sits upon a blue liminal layer of a custom-made calico blanket, filled with tiny river stones that have been sewn into evenly-balanced sections. This weighting is designed to be around a tenth of a person's body-weight and provides a calming layer of protection as they prepare for, or rest in, or recover from one of life's journeys. A final layer of soft blue polyester sits where the blanket touches the body. This is our weighted blanket.

\section{Be Longing}

Kōwaī̄hau? Who am I?

Where do I belong?

Creative Arts in Education and Therapy - Eastern and Western Perspectives - Vol. 4, Issue 2, December 2018.

(c) 2018 Inspirees International. Creative Commons Attribution-NonCommercial-NoDerivs 2.0 Generic License 


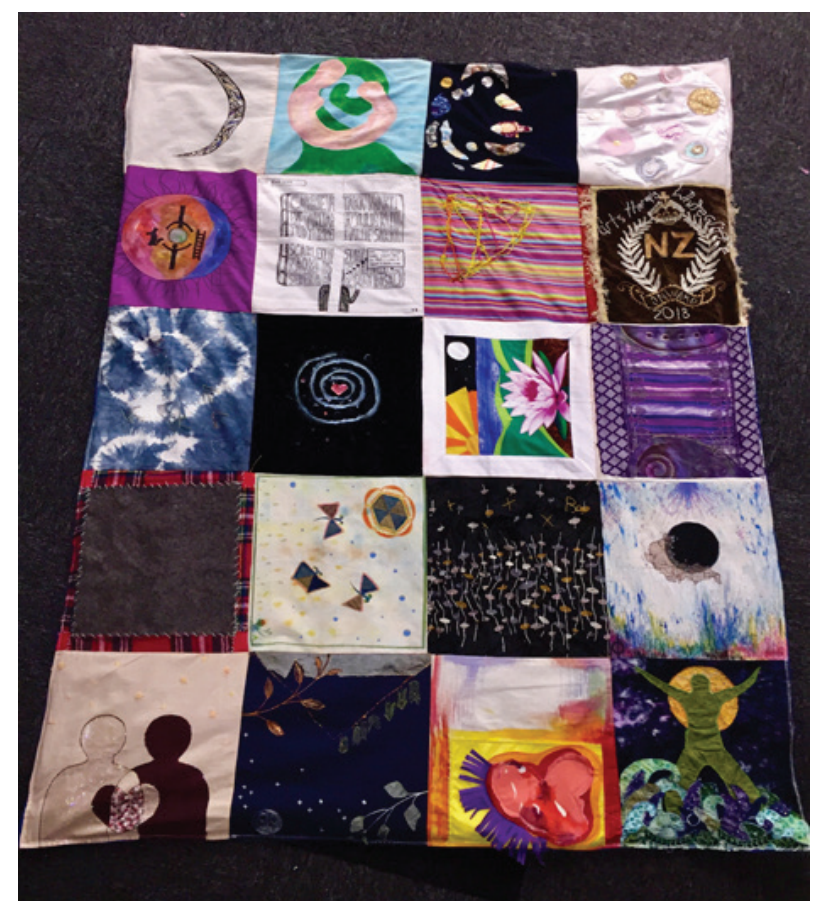

FIGURE 1 | 'The Quilt' (MAAT year 3, September 2018)

To longing,

connection,

people, earth, water,

creation or creator?

Not knowing

creates a space for you to teach me

in rich detail,

to trust and take risks.

When I'm all at sea I can float.

Your story, my story, their stories, our stories are connected.

Be still, be quiet, breathe

Tihei Mauri Ora!

There is life. 
Can we offer

find, make a home

here with art

amongst the gorgeous

and dangerous

shadows cast

moving and still

beings

You hand me

a brush

You lend me

your colours

I paint beside

with, within

tears stitched finely quietly

transforming

into wild birds

skwarrk!!

wings creak wings sing

wings joining in creating

a strong and beautiful

formation

and then

the sky changes...

watch them

swooping, diving, seeking

defining drawing

into clear and open

spaces

$\sim$

Whilst climbing up and down the ladder of my life I became intrigued by the process of giving birth to things from nothing and I started to realise that whatever art I created by my own hands was basically a response to the general human condition, to our mutual terrain, similarly to the quilt where we shared every inch of thread and turned personal into communal. I feel 
magically connected to these creative warriors who are dedicated to respond with art to suffering and inspired to perceive what is broken and fragile as wholesome and beautiful.

\author{
Patches sewn by another \\ for me to fill \\ with my own creation \\ I wonder how to fill the empty space \\ with its neatly stitched borders \\ it's up to me \\ to decide \\ what happens right now \\ I don't want to sketch out every \\ detail or \\ define every object in soft neat \\ erasable pencil \\ before I begin \\ I pull out a black pen, \\ permanent, and \\ Ijust begin
}

We gathered in a high room one evening after class. With churning emotions, we spoke about the fast-approaching end to our time as student arts therapists and began to discuss a way to show our tutors our deep appreciation for their guidance during these enshrining years. This discussion vacillated between gestures of gratitude and pragmatic gifts until the two coalesced into our final offering - a weighted blanket; a quilt of many colours.

A custom weighted blanket-maker was contacted whilst measurements were divided, lists were written, and plans were developed. We looked around, nodding: over time and distance, between the layers of our lives, we would do this.

We exchanged countless emails over the following months. We agreed: in our separate spaces, we would source and create our individual squares before tucking them away, ready to be brought back out when we would meet again.

\title{
Our creative threads
}

A With)nessing 
An honouring

Side by side

As one

Like a pride of lions, awakening from a deep sleep

Us!

Hear us growl! Hear us howl!

Celebrating!

Humbling...

Grieving...

Gratitude.

A chaotic creative metamorphic force

Raw resonance hemmed together

Fabrics that reference me as part of an us

An us of strength and warmth

An us that has shrouded me and held my vulnerabilities

And my emergence

I note my beginnings and roots

A tartan that warms the wearer

Rustic stitches

To a soft woollen centre

The centre each have helped form

And I am stitched to you, as you are to me

Our boarders touching

Our colours complementary

The stories of our journey together held

In one piece

Starting as a seed, scared fragile and small

we arose.

Fractals weaving to form one,

among a galaxy that is limitless

three stars flicker for the years flown by.

Together traversing this mountainous range 
strengthening our ties travelling across rocky tides, a mesh of co-existing light and dark, dark and light.

A forest of rhizomatic trees

And fledgling birds about to take flight,

We are both and...

A tapestry of holding, wonder and shared delight!

Our layer of trusting makes miracles happen.

The day came when we gathered once more in the high room to reveal our creations and begin the process of connection. A pause.

'Here's mine', 'Here's mine'.

Our pieces were delicately placed upon the floor to create a variegated field of coloured patches. A deep, collective breath was drawn before an exhaling of pride, surprise and joy.

And then back to it. Some of us stitched our last-minute shapes to our squares whilst others measured and chalked outlines. Some trimmed and pinned, some ordered food, and some drove the dim murmur of the sewing machines.

'Where does each piece sit?','What still needs to be done?', 'Where are the pins?', 'Can I borrow that thread?', 'Pass me the scissors please.', 'Does anyone want snacks?','Did you notice the moon tonight is exactly like her moon sewn here?'

Separate pieces were stitched together in twos and threes, laid out, pinned, sewed again, more and more, until the last pieces were finished. This layer was complete; all squares were now connected. Our quilt was bundled, gleaming, into a backpack; prepped and ready to be attached to its weighty counterpart.

Across the black material is a row of lines, each strung with variously tilted disks that suggest levels, stages or a progression of beads. Each strand stands alone but form an overall pattern. Each of us as students in the Arts Therapy Masters programme, stood together seminar after seminar, and yet so much on our own, achieving our differing but similar stages of development, pushing past the beads of one milestone after another, towards realizing ourselves as creative arts therapists.

We are walking with mountains and moons, 
A dark gracious landscape, flapping, growing, breathing,

Booming deep oceans, and still light all around.

The seasons, chaos, play, change - these living creatures, I have been introduced to them.

These mountains hold hands, and bend to visit us who live on and around and inside their wings,

We move on their shoulders, gather snippets of their conversation, and breathe their aroma,

We expand, and my body moves on and on to their gracious booming.

We are here, each with a bag of whispers, tools for play, and our own tatters and ribbons,

We learn to dive, to notice, to receive, to share this breath.

We have felted together the first page of our story,

And we walk with mountains and moons.

Being, together

I put my heart next to yours.

Mine is embroidered with moments from my life.

Yours is embroidered with moments from yours.

With needle and thread, we gently weave our two pieces together.

I fold my edge and give one of them to you.

You fold your corners and pass one of them to me.

Together we assemble our rough edges and mend our broken hearts.

One stitch forward,

One stitch backward,

A step forward, toward each other

A step backward from each other.

We create a mindful spacing.

With sincerity, you and I connect.

I don't ask you to resemble me.

You don't force me to be like you.

Over time we become, each other, side by side.

Me as I am, you as you are. 
United, and stitched loosely together.

And now willing to share our unique edges with others.

$\sim$

We created, we moved, we felt, we challenged, we wept, we broke, we breathed, we stretched, we laughed, we absorbed, we acknowledged, we observed, we shared. Each patch of gratitude is holding the learning that was abundant, weaving together with a thread that contains each of us. I am part of the whole, rich in memory, understanding what we came with, has been transitioned.

We see who we are now. We listen. Be

An ill-timed courier crisis caused a commotion of texts, a late evening drive, a gentle meeting at a quiet doorway, and a hefty wrapped box sitting on the car seat. Then again in a high room a handful of sewers, energized with determination, gathered with their lunches. The body of the blanket was unboxed and draped over the table. The quilt was then laid over, and pinned. We pulled at it, tacked corners down, and discussed thread colours and strengths. With every tug we came to feel more and more at home with the heavy, beautiful creature that we had created. Sewing machines were fired up once more and it seemingly all-at-once came into being - our beautiful weighted blanket.

Shifts and stitches, in time

Under and over, through and within

Emergent from a shadow, past

Leaning into the Onward future

My peace with pieces, in process

A conjurer of the old and the new

From my Pākehā nationality (of strife and ...)

An honouring of bicultural practice

Whakapapa, emergent

I lean into others

Sharing and threaded, alongside

My bricoleured felt sense

Forming a collegial whole

Of the magic, to come

A collective energy, unmatched 
And a Korowai for others yet to arrive

$\sim$

weaving in

round

through

$i$ don't know

what's me

and you

$\sim$

Stitch these squares into the folds of your belly, remembering how once you were frightened to begin threading these into the pleats of your memory

of time and tears

tumbling into the night

Seams sewn

into the fabric of your exalted

being,

cultivating the blessing of square miles crossed

to arrive, annihilated,

only to be created.

$\sim$

We walk our singular journeys together.

A powerful tribe.

And finally we place a small part of us.

Gathered in person

Gathered in creating

To gather as unique spirits in unity

Together a whole

Sewn with threads like the net of Indra.

Creating something new and beautiful

Poiesis 
For ourselves

For future students

And clients we have yet to meet.

Our blanket is our way of honouring the connections that we have formed within and between ourselves, our tutors, and our profession. It is a recognition that we are who we are through our relationships with one another. This gift is both colossal and contained; robust and delicate; weighty and gentle. It is the result of heartfelt gratefulness, communal co-dependency, gumption, dialogues, and the act of simply being together. Our blanket is our cohort: who we are, who we were, and who we hope to be.

soft-bodied soul

albino skin (pockmarked, but porous)

oozes from the tepid pond to

collapse upon its cool clay embankment

quivering

(softly ribbiting)

gulping in the sweet morning air

of the new day's still dark dawn

We carry a golden thread in our beaks

Stitch it between and through the layers

Up, down, up, back, down -

It's the work of patches

A patched work

Patched lives and stories

Patched possibilities

We create new layers to strengthen the old

This patch, my patch, your patch, Our patch-

Each patch a piece of me and of you

Stitched together, a piece of Us

Now we fly,

In the same direction

and in different directions 
Wearing our colours like victory flags

Up, down, up, back, down-

Each carrying the golden thread in our beaks

To stitch into our next patched masterpiece.

\section{Emerging}

the ruru* ruffles comfortable feathers

on the brink of the elements.

her korowai** wrapping her

a campfire blanket

lingering she sways between

comfort and the groans of the ngahere***.

Raindrops roll off feathers, she

collects the drops

drinks deeply

bitter sweet

offering to share in colourful communion

nods and smiles through tears

Flies by night, dreamtime

curious creatures flock

bizarre, wonder-ful souls

play and sigh and breathe and build and paint

their way home

or perhaps it's somewhere new.

*Ruru - TeReo for New Zealand's native owl

**Korowai - a type of Māori cloak

***Ngahere - TeReo for forest

Descriptions retrieved from: http://maoridictionary.co.nz 17th September 2018

Someone says "A gift!"

"A patchwork quilt"

follows hot on their tail. 
We are [re?] making our-selves...

The snipped and stitched,

bits and bobs,

harmonious

and hard edged.

There is chaos for a while,

Can this be made?

Will it be made?

The uncertainty sits in the space between.

Us. And still we cut and glue and mould.

Something resembling an identity.

A therapist.

Someone to sit with the tangles,

the tattered or torn, to breath in

the pieces and say;

"it might be made into a whole,

and if it isn't,

I love it anyway".

This patched and zigzagged creation

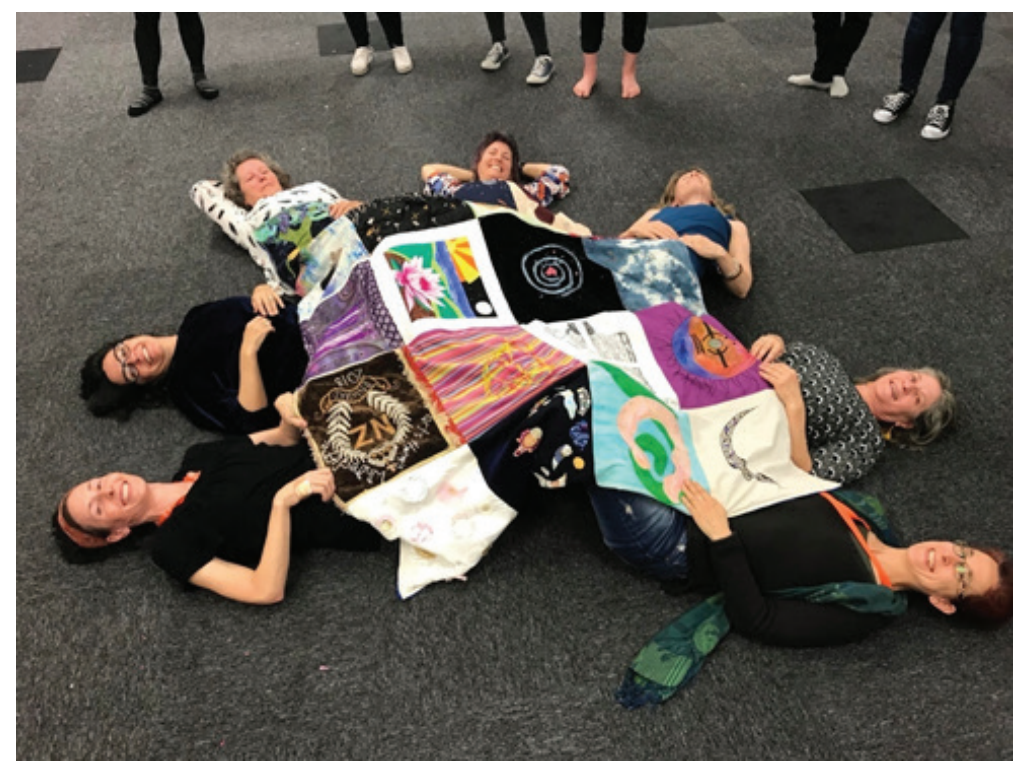

FIGURE 2 | The Quilt; Gifted (MAAT year 3, September 2018) 
is a sign pointing to therapist-born.

A gift found, made of me-ness and you-ness.

And given to whoever needs warm.

\section{About the Authors}

Allie Manners: Back straight, feet in the earth...kinda wanderer.

Arijana Ruznic-Beyer: Soulloguer.

Ayaka Shima: Trainee Arts Therapist, Japanese Society of Certified Clinical Psychologists, and cheeky bird.

Beth McGuinness: Arts Therapist, teacher, art lover.

Brett Harrington was working as an ADHD coach and counsellor when she decided to gain Arts Therapy skills. She is now also working creatively with children with autism. Carrie Leigh: BVA, GradDip (Art History), PGDip (Arts Therapy), almost MAAT, quiet collage-maker.

Danielle Mitchell has a background in primary teaching (BEd) and almost MAAT, and dabbles in illustration.

Eve Cunnane: Cert (Media Arts), BA (Philosophy \& English), PGDip (Arts Therapy), Trainee member ANZACATA.

Istvan Csata: open sky istvan, art worker.

Judy O'Byrne: BN PG Dip Health Science (CBT), PGDip (Arts Therapy), Member NZAC and trainee member ANZACATA.

Julie Dobson: moon cherisher, artist and MAAT student.

Louise Morton: BA, PGDipTchg (Primary), PGDip (Arts Therapy), arts adventurer.

Mary Weir:PgDip. Art Therapy, BA Circus and Physical Theatre, Adv. Dip. Fine Art, Cert. Adult Education, Cert. Disability andAged Care, Yoga Instructor and general philosophical coddiwomple-er.

Naomi Pears-Scown: BA, nearly MAAT, stepping softly, creating gently.

Renee Barker: BFA, PGDipEd (Secondary), PGDip (Arts Therapy), trainee member ANZACATA, creative fun-lover.

Rosa Heney: Supporting communities through creative practice, BFA, Dip Adult Ed, Dip Teaching (Secondary), PGDip (Arts Therapy).

Ruth Foulkes: MA(Ed), BA(Hons), PGDip (AT), PGCE, Trainee Arts Therapist. Primary trained teacher, teacher educator, mentor, coach and facilitator.

Sarah Moore: BFA (Photography), PGDip (Arts Therapy).

Scarlett Jeong: BA, GradDip (TESOL), PGDip (Arts Therapy).

Serena Corless: BMA (Photography), PGDip (Arts Therapy), soon MAAT, passionate creative being. 